International Journal of Thermofluid Science and Technology (2019)

Volume 6, Issue 1, Paper No. 19060101

https://doi.org/10.36963/IJTST.19060101

\title{
|Tㄷㄴ
}

Research Article

\section{Numerical simulation of convective heat transport within the nanofluid filled vertical tube of plain and uneven side walls}

\author{
M. J. Uddin 1, A. K. M. Fazlul Hoque', M. M. Rahman², K. Vajravelu \\ ${ }^{1}$ General Educational Development, FSIT, Daffodil International University, Dhaka-1207, Bangladesh \\ ${ }^{2}$ Department of Mathematics, College of Science, Sultan Qaboos University, P.O. Box 36, P.C. 123 Al- \\ Khod, Muscat, Sultanate of Oman \\ ${ }^{3}$ Department of Mathematics, University of Central Florida, Orlando, FL 32816, USA
}

Received: 12 June 2019; Received in revised form: 28 August 2019; Accepted: 10 October 2019;

Published online: 10 November 2019

(C) Published at www.ijtf.org

\begin{abstract}
Two-dimensional transient natural convective flow in a vertical tube of plain and uneven sidewalls containing cobalt-kerosene nanofluids is analyzed using a nonhomogeneous dynamic model. The vertical right wall of the enclosure is maintained at a constant low temperature and the left wall is heated by a uniform thermal condition whereas the horizontal side-walls are insulated. The Brownian motion and thermophoretic phenomena of the nanoparticles are considered in the model. The governing nonlinear momentum, energy, and concentration equations are solved numerically using a Galerkin weighted residual finite element method. The thermal, flow and concentration fields are obtained to understand the flow dynamics of cobaltkerosene nanofluid in two types of enclosures. The local and average Nusselt numbers are analyzed for plain and uneven side walls of the tube for different parameters of the problem. The simulated results are compared with the experimental as well as with the numerical data available in the literature for some special cases. The outcomes show that the tube of having uneven vertical side-walls give higher heat transfer for lower values of the thermal Rayleigh number; whereas for the higher values of the thermal Rayleigh number, the tube of plain vertical side-walls exhibit significantly higher heat transfer rate.
\end{abstract}

Keywords: Nanofluid; Nanoparticles; Convection; Heat transfer; Finite element method; Even and uneven walls 
M. J. Uddin et al.

International Journal of Thermofluid Science and Technology (2019), Volume 6, Issue 1, Paper No. 19060101

\begin{tabular}{|c|c|c|c|}
\hline \multicolumn{4}{|c|}{ Nomenclature } \\
\hline$C$ & concentration $\left(\mathrm{mol} / \mathrm{m}^{3}\right)$ & $(\mathrm{U}, V)$ & $\begin{array}{l}\text { dimensionless velocity } \\
\text { components }\end{array}$ \\
\hline$C_{c}$ & reference-concentration $\left(\mathrm{mol} / \mathrm{m}^{3}\right)$ & $(x, y)$ & dimensional coordinates $(m)$ \\
\hline$c_{p}$ & specific heat $(J / k g K)$ & $(X, Y)$ & dimensionless coordinates \\
\hline$D_{B}$ & $\begin{array}{l}\text { coefficient of the Brownian diffusion } \\
\left(m^{2} / s\right)\end{array}$ & & \\
\hline$d_{p}$ & nanoparticle size $(\mathrm{nm})$ & \multicolumn{2}{|c|}{ Greek symbols } \\
\hline$D_{T}$ & coefficient of thermal diffusion $\left(\mathrm{m}^{2} / \mathrm{s}\right)$ & $\alpha$ & thermal diffusivity $\left(\mathrm{m} / \mathrm{s}^{2}\right)$ \\
\hline$g$ & the acceleration for gravity $\left(\mathrm{m} / \mathrm{s}^{2}\right)$ & $\beta$ & thermal expansion $(1 / K)$ \\
\hline$k_{B}$ & constant (Boltzmann) $(J / K)$ & $\beta^{*}$ & mass expansion $(1 / K)$ \\
\hline$L$ & the bottom wall length $(m)$ & $\xi$ & nondimensional time \\
\hline Le & Lewis number & $\rho$ & density $\left(k g / m^{3}\right)$ \\
\hline $\mathrm{Nu}$ & Nusselt number & $\mu$ & dynamic viscosity (Pas) \\
\hline$N u_{a v e}$ & average Nusselt number & $\theta$ & dimensionless temperature \\
\hline$N_{T B T C}$ & dynamic diffusion parameter & $\phi$ & nanoparticles volume fraction \\
\hline$N_{T B T}$ & dynamic thermo-diffusion parameter & $\Phi$ & dimensionless concentration \\
\hline$n$ & empirical shape factor of nanoparticles & $\kappa$ & thermal conductivity $(W / m K)$ \\
\hline$p$ & nondimensional pressure $(P a)$ & $\psi$ & stream function \\
\hline$P$ & dimensionless pressure & $\Psi$ & the sphericity of the nanoparticles \\
\hline $\operatorname{Pr}$ & Prandtl number & $\Delta C$ & $\begin{array}{l}\text { concentration difference } \\
\left(\mathrm{mol} / \mathrm{m}^{3}\right)\end{array}$ \\
\hline$R a_{T}$ & local thermal Rayleigh number & $\Delta T$ & temperature difference $(K)$ \\
\hline$R a_{c}$ & solutal Rayleigh number & & \\
\hline$S c$ & Schmidt number & Subscri & \\
\hline$t$ & dimensional time $(s)$ & $n f$ & nanofluid \\
\hline$T$ & temperature $(K)$ & $b f$ & base fluid \\
\hline$T_{h}$ & temperature of the hot wall $(K)$ & $p$ & nanoparticles \\
\hline$T_{c}$ & temperature of the cold wall $(K)$ & ave & average \\
\hline$(u, v)$ & dimensional velocity components $(\mathrm{m} / \mathrm{s})$ & & \\
\hline
\end{tabular}

\section{Introduction}

The commercial use of nano-sized particles with conventional fluids which are called nanofluid increases day by day due to the enhanced productiveness of these mixtures. The research on nanofluids is important as well as attractive features in the nanoscience and nanoengineering communities because of the industrial requirements for commercialization and 
M. J. Uddin et al.

International Journal of Thermofluid Science and Technology (2019), Volume 6, Issue 1, Paper No. 19060101

applications. The most important objective of this research in nanofluids is to attain the maximum conceivable outcomes for the nethermost imaginable price and weather the functioning stuff for lengthier epochs of time. The varieties of applications and the prospect of nanofluids in several fields are available in the literature. Already in the numerous sectors, nanofluids are being used, as for example, for cooling of engines, nuclear system, and electronics. Outstanding results of nanofluids have been reported in the heat exchangers for the heat transfer application. Nanofluids give more heat transfer than conventional fluids. In the biomedical application, in a fuel cell, domestic refrigeration, and the drilling, nanofluids are used significantly. The applications and the potentiality of nano-mixtures are available in the literature (Das et al., 2007; Choi, 2008; Huminic et al., 2012). Size of the particles of nanofluids is an important matter in making them stable. Many investigations on the effects of the size of solid particles in the mixture are available in the literature. For instance, Choi (2009), Piletska and Piletsky (2010) and Uddin and Hoque (2018) have analyzed the effect and morphology of the nanoparticles size. An outstanding review of the nitty-gritty of nanofluids with its development and claim can be found in Uddin et al. (2016).

Nanofluids flows are very complex. The complexities in the flow dynamics increase during the flow. Hence, there are many challenges in describing the nanofluids flows theoretically and mathematically. However, many efforts are made and several ideas are available in the literature to distinguish nanofluids. As for example, one-component posturing, particle migration approach, particle dispersion approach, and the two-constituent modeling are available in the open literature of nanofluids. There are many arguments regarding the advantages and disadvantages of nanofluids modeling. Recently, Uddin et al. (2017) studied the nonhomogeneous dynamic mathematical model to describe the behavior of nanofluids. Using this model, some serious disadvantages of the other four types of representations have been eradicated. Some heat transfer related problems are also solved using this model (Uddin et al., 2016, 2017a, 2017b) and the improved heat transfer coefficients are reported.

Nowadays, the numerical studies on natural convective heat transfer of nanofluids inside cavities designed on the practical phenomena are one of the most attractive and demanding fields of the research communities due to their industrial applications. In the geophysical sciences, mechanical industries and industries of the electronic devices, heat transporting from one object or medium to the one more object or medium or cooling down the items are crucial phenomena and persistent requirement. To obtain the maximum heat transfer results so that the items can be lasting long in these manufacturing requests, the patterns and shapes design of the objects are necessary stuff. Using the experimental equipment's and components for finding the best shapes of the objects, the repeated experimental test is required which is very much costly. In these cases, simulating the manufacturing objects to find the perfect design using repeatable perfect numerical techniques are very famous among scientists.

The free convection heat transfer rate analysis inside a vessel taking diverse forms of the walls has been the attention of numerous researches in the topical eons. These are for the reason of the mounting requirement for a recovering empathetic of this spectacle in engineering and the technological applications. As for example, for the electronic packaging, cooling of the computer motherboard passive block, food processing, solar collector-receiver and cooling-channels of 
M. J. Uddin et al.

International Journal of Thermofluid Science and Technology (2019), Volume 6, Issue 1, Paper No. 19060101

nuclear reactors, different types of shapes need to be investigated to find the best possible heat transport. Many studies exist on the numerical investigation of natural convection heat transfer in a vessel of taking various trials of shapes bestowing to the desires.

Considering various combinations and the shapes of the geometry, Sasmito et al. (2011) studied the convective heat transfer enhancement utilizing copper oxide-water and alumina-water nanofluids flow in different coiled square tubes. Their results showed that plane spiral tubes exhibit better performance in heat transferring for nanofluid than the other coiled tubes. They argued that the convective heat transfer is possible to enhance by altering the flow and shapes of geometry. Akhavan-Behabadi et al. (2012) have studied experimentally the heat transfer enhancement in the entry length region of the helically-coiled tubes utilizing nanofluid flow. In their experiment, they have considered the nanofluid flow in the straight-helical cylinders with isothermal boundary conditions. They have shown that based on the experimental data, applying helically coiled tubes as a replacement for straight ones improves heat transfer rate extraordinarily. They also showed that the combination of two increasing methods has an extraordinary competency to increase the heat transfer rate. An interesting experimental study on the thermophysical properties and overall performance of heat transfer oil nanofluids with multiwalled carbon nanotube flow inside the vertical helically coiled tubes have been conducted by Pakdaman et al. (2012). In this experiment, the laminar flow of nanofluids on the thermal entrance region of the helically coiled tubes has been investigated by the isothermal boundary condition. The optimal work conditions and the performance index are determined and their result shows the higher overall performance index of up to 6.4. Also, altering the shape of the inner wall, Uddin et al. (2017b) numerically examined the transient natural convective heat transport in homocentric annuli containing nanofluids accompanying an oriented magnetic field using a nonhomogeneous dynamic mathematical model. Their results show that 1-20 nm size nanoparticles are stable and uniform in the base fluid. The elliptic shape of the inner wall exhibits a higher heat transfer rate. Tremendous attempts have been made in the past to analyze the nanofluid flow and heat transfer within different types of enclosures altering the boundary shapes and conditions. The noteworthy numerical inquiry of natural convection heat conveyance on enclosings employing nanofluids such as Sun et al. (2016), Lun-Chun et al. (2008), Lotfi et al. (2010), Bianco et al. (2011), Mahian et al. (2014), Alam et al. (2014), Yan et al. (2017), Rahman (2018), and Rahman et al. (2019).

In the present study, our aim is to analyze the heat transfer rate in a cobalt-kerosene nanofluid filled tube considering plain and irregular shapes of the left and right walls using a nonhomogeneous dynamic mathematical model. Cobalt-kerosene nanofluid is used in this investigation because it has many potentialities in the applications. Also, Uddin et al. (2018) studied different nanofluids and showed that cobalt-kerosene nanofluid exhibits a higher heat transfer rate. Also, separately, cobalt nanoparticles and the kerosene have many advantages and discretely, they are using in many branches. The manufacturing process of cobalt nanoparticles is convenient. They are mostly sphere-shaped, and their appearance is a grey or black powder. The laser evaporation method can be used to produce cobalt nanoparticles. The raw material cobalt is used to produce cobalt nanoparticles of high purity, small size and high activity in a larger scale at low cost. They can be packaged in antistatic plastic bags. The applications of cobalt 
M. J. Uddin et al.

International Journal of Thermofluid Science and Technology (2019), Volume 6, Issue 1, Paper No. 19060101

nanoparticle are comprehensive. They have magnetic properties, which leads to applications in sensor and imaging sectors. They exhibit distinct magnetic properties compared to bulk materials. By using them, absorbers with the relatively low volume fraction of metallic inclusions can be made. The cobalt nanoparticles are using in many sectors such as medical sensors, biomedicine as a contrast enhancement agent for magnetic resonance imaging, coatings, site-specific drug delivery agents for cancer therapies, plastics, nanofibers, nanowires, textiles, and highperformance magnetic recording materials, microwave-absorption materials and as a magnetic fluid-made of iron. Cobalt particles can also be used in several military applications such as high-performance invisible materials for absorbing extremely high-frequency millimeter wave, perceptible light and electromagnetic. Investigators are beholding into discovering their imaging, electrical, thermal, magnetic, ophthalmic, dielectric, catalytic, bioscience and biomedical properties for more applications.

In the nanofluids literature, very less attention is given on the base fluid as kerosene even though it has many applications. As a fuel, kerosene is used for cooking, lighting, and heating. It is utilized as a culinary fuel in a transported kitchen appliance. As a heating fuel, it is frequently used in portable stoves and is traded in some filling stations. During power failures, it is used as a heat source. Jet fuel is another important use of kerosene. It is also applied to foil air from resolving in a boiling liquid. Circus actors, stage effects and other live performances which comprise fire, use kerosene because of its low fire temperature. As a petroleum product miscible with many industrial liquids, kerosene can be used as both a solvent, able to remove other petroleum products, such as chain grease, and as a lubricant, with less risk of combustion. In metal production and treatment, it can also be used as a cooling agent. Kerosene can be employed locally to hard-to-get-rid of the adhesive agent left by stickers on a glass surface. Hence, it is expected that the combination of the properties and actions of cobalt nanoparticles and kerosene can be applied in the applications instead of the individual components, the cobalt or kerosene.

We have chosen tube-shaped enclosure because of a wide range of applications in the field of computer, civil, mechanical and architectural engineering. Especially, two types of tubes where one type of tube designed with uneven boundaries and another is a plain tube have comprehensive possibilities for use in the nuclear reactor, solar thermal collector, computer, electronic, and electrical devices. As for example, the computer motherboard passive block can be extremely heated and heat must be transferred from the device to the other parts of the system so that the performance of the device can be optimal. In this case, the better design and cooling substances should be investigated for the other part of the system. A tube utilizing nanofluids cooling can be a solution for heat transferring in this kind of system. Also, several shapes of tubes are used in refrigeration, air conditioning, heating, and ventilation system. Nevertheless, comparatively, a very rare numerical experiment is done on natural convective heat transport inside a nanofluid filled tube of altering the shape of the boundaries. The performances of the wall shape of the tube for base fluid and nanofluid are the foremost focus in the present study. The vessel familiarized in this article can have an excessive usage for cooling the motherboard in a computer industry and making solar collectors in the solar industry, the numerical analysis represented can benefit to encourage the practice of renewable energy. 
M. J. Uddin et al.

International Journal of Thermofluid Science and Technology (2019), Volume 6, Issue 1, Paper No. 19060101

\section{Problem Formulations}

\subsection{Physical Modeling}

Bearing in mind a realistic application, the physical model of the problem has been shown in Fig.1, where the Cartesian coordinates are $x$ and $y$. The tubes with plain and uneven left and right-side walls filled with cobalt-kerosene nanofluid are considered. In this case, the no slippery conditions for the entire boundaries are adopted in the problem. The walls condition of the leftover even as well as uneven boundaries of the cavity are modeled as $T=T_{h}$. The temperature of the right even and uneven boundaries of the enclosures is comparatively lower where heat can be passed through it. These walls are postured as $T=T_{C}$, where $T_{h}>T_{C}$. The other two horizontal walls of the enclosures are assumed as adiabatic where heat cannot be lost or gained. In the preliminary stage of the mixture, the nanofluid concentration is assumed a lower concentration $C_{c}$. For over the periods of time $(t>0)$, the nanofluid concentration is considered high $\left(C_{h}\right)$ within the enclosure such a way that $C_{C}<C_{h}$. In the present numerical simulation, a comparative study on the effect of the two different shapes of the left wall of the cavity for the problem's pertinent parameters is the primary concern.

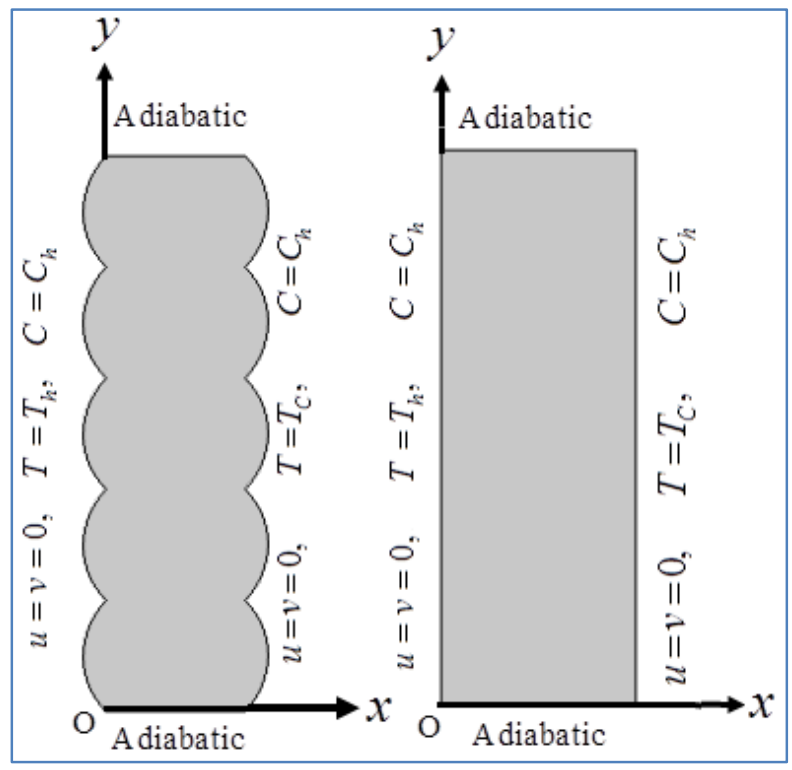

Fig. 1 Flow configuration and schematics geometry of the system.

\subsection{Mathematical Modeling}

\subsubsection{Governing Equations for Nanofluid}

To explain cobalt-kerosene nanofluid in the tubes, the nonhomogeneous dynamic model has been considered. The effects of gravity, Brownian motion, and thermophoresis of cobalt nanoparticles are encompassed in the model. The chemical reaction between the nanoparticle and the base fluid is neglected in the model because the activation energy of nanoparticles is not given in the mixture so that the chemical bonds of the particles can be broken. There is also no 
M. J. Uddin et al.

International Journal of Thermofluid Science and Technology (2019), Volume 6, Issue 1, Paper No. 19060101

proper orientation among the nanoparticles are assumed so that chemical reaction can be measured. Also, the thermal radiation is not considered in this study. It is assumed that the mixture is equilibrium. The size of the nanoparticles is very tiny. The cobalt nanoparticles are considered as the species of kerosene. The conservation equations that mean, continuity, momentum in $x$-direction, momentum in $y$-direction, energy, and concentration equations are as follows respectively (Uddin, and Rahman, 2017; Uddin et al., 2016, 2017a, 2017b):

$$
\begin{aligned}
& u_{x}+v_{y}=0 \\
& \rho_{n f}\left(u_{t}+u u_{x}+v u_{y}\right)=-p_{x}+\mu_{n f}\left(u_{x x}+u_{y y}\right) \\
& \rho_{n f}\left(v_{t}+u v_{x}+v v_{y}\right)=-p_{y}+\mu_{n f}\left(v_{x x}+v_{y y}\right)-g(\rho \beta)_{n f}\left(T_{c}-T\right)-g\left(\rho \beta^{*}\right)_{n f}\left(C_{c}-C\right) \\
& T_{t}+u T_{x}+v T_{y}=\alpha_{n f}\left(T_{x x}+T_{y y}\right)+D_{B}(C)^{-1}\left(C_{x} T_{x}+C_{y} T_{y}\right)+D_{T} T^{-1}\left[\left(T_{x}\right)^{2}+\left(T_{y}\right)^{2}\right] \\
& C_{t}+u C_{x}+v C_{y}=D_{B}\left(C_{x x}+C_{y y}\right)+C D_{T} T^{-1}\left(T_{x x}+T_{y y}\right)+D_{T} T^{-1}\left(C_{x} T_{x}+C_{y} T_{y}\right)
\end{aligned}
$$

where $u$ and $v, g, p, T_{c}, T, C_{c}, C, \mu_{n f}, \rho_{n f},(\rho \beta)_{n f} \alpha_{n f}, \kappa_{n f},\left(\rho \beta^{*}\right)_{n f},\left(\rho c_{p}\right)_{n f}$ are the velocities in $x$ and $y$ coordinates, gravity, pressure, constant temperature, temperature, nominal concentration, the concentration, the dynamic viscosity, density, thermal expansion thermal diffusivity, thermal conductivity, mass expansion, the heat capacity of nanofluid respectively. The relations of the thermophysical properties of nanofluid are quite difficult to justify. However, the famous correlations used in many kinds of literature have been selected for the present study. In view of the investigation of Sheikholeslami et al. (2013), Maxwell (1881), Khanafer et al. (2003), Tiwari and Das (2007), and Rahman et al. (2015), Xuan et al. (2003) and Uddin et al. (2017a), the following correlations of the thermophysical properties of nanofluid are used in the simulation:

$$
\begin{aligned}
& \alpha_{n f}=\kappa_{n f}\left(\rho c_{p}\right)_{n f}^{-1} \\
& \mu_{n f}=(1-\phi)^{-2.5} \mu_{b f} \\
& \rho_{n f}=\rho_{p} \phi-\rho_{b f}(\phi-1) \\
& \left(\rho c_{p}\right)_{n f}=\left(c_{p} \rho\right)_{p} \phi-(\phi-1)\left(c_{p} \rho\right)_{b f} \\
& (\beta \rho)_{n f}=(\beta \rho)_{p} \phi-(\beta \rho)_{b f}(\phi-1) \\
& \left(\beta^{*} \rho\right)_{n f}=\left(\beta^{*} \rho\right)_{p} \phi-(\phi-1)\left(\beta^{*} \rho\right)_{b f} \\
& \frac{\kappa_{n f}}{\kappa_{b f}}=\frac{(n-1) \kappa_{b f}+\kappa_{p}-(n-1) \phi\left(\kappa_{b f}-\kappa_{p}\right)}{(n-1) \kappa_{b f}+\kappa_{p}+\phi\left(\kappa_{b f}-\kappa_{p}\right)}+\frac{\rho_{p} c_{p} \phi}{2 D_{T}^{\ell}} \sqrt{\frac{2 k_{B} T_{C} D_{T}}{3 \pi \mu_{n f} d_{p}}}
\end{aligned}
$$

Here, $D_{T}, D_{T}^{\ell}, k_{B}, d_{p}, n=3 / \Psi$ and $\Psi$ the thermophoresis coefficient, the absolute value of $D_{T}$, the Boltzmann constant, solid's shape factor and sphericity of nanoparticle respectively. In the present study, we have taken spherical shaped nanoparticles where $\Psi=1$ (Timofeeva et al., (2009). Also, the coefficients of the random motion and the thermophoresis dispersion coefficient are used as (Uddin et al., 2016):

$$
\begin{aligned}
& D_{B}=k_{B} T_{C}\left(3 \pi \mu_{n f} d_{p}\right)^{-1} \\
& D_{T}=0.126 \kappa_{n f} \lambda^{*} \beta_{b f} \mu_{n f}\left(\kappa_{b f} \rho_{n f}\right)^{-1}
\end{aligned}
$$


M. J. Uddin et al.

International Journal of Thermofluid Science and Technology (2019), Volume 6, Issue 1, Paper No. 19060101

where, $\beta_{b f}$ and $\lambda^{*}$ are thermal expansion of base fluid and the dimensionless correction factor, respectively.

\subsubsection{Boundary Conditions}

The suitable opening states and the wall conditions for the existing problem are as follows:

For $t=0$, the entire domain of both enclosures:

$$
p=0, u=v=0, T=T_{C}, C=C_{C},
$$

For $t>0$,

On all the walls: $u=v=0, C=C_{h}$

On the left even and uneven walls: $T=T_{h}$

On the right even and uneven walls: $T=T_{C}$

On the two horizontal insulated walls of the cavities: $\frac{\partial T}{\partial n}=0$

\subsubsection{Non-dimensional Governing Equations}

The governing equations (1)-(5) are dimensional. Use of dimensionless governing equations for numerical simulation is a usual practice in fluid dynamics research. There are some benefits to make the dimensional equations into nondimensional such as (i) the controlling flow parameters of the problem can be easily identified, (ii) it is free from dimensional barriers and (iii) the results can be generalized. Let us introduce the following non-dimensional variables for the present governing equations:

$$
U=\frac{u L}{\alpha_{b f}}, V=\frac{v L}{\alpha_{b f}}, X=\frac{x}{L}, Y=\frac{y}{L}, \theta=\frac{T-T_{C}}{\Delta T}, \mathrm{P}=\frac{p L^{2}}{\rho_{b f} \alpha_{b f}^{2}}, \xi=\frac{\alpha_{b f} t}{L^{2}}, \Phi=\frac{C-C_{C}}{\Delta C}
$$

where, $L, \alpha_{b f}, \Delta C=C_{h}-C_{C}, \Delta T=T_{h}-T_{C}, C_{C}$ and $T_{C}$ are the length of the cavity, base fluid's thermal diffusivity, the concentration difference, temperature difference within the cavity, the fixed concentration and temperature respectively. Now, applying the dimensionless variables (16) to the conservation equations (1)-(5) we have the following dimensionless equations:

Continuity equation:

$$
U_{X}+V_{Y}=0
$$

Momentum equation in $X$ - direction:

$$
\begin{aligned}
& U_{\xi}+U U_{X}+V U_{Y}=-\rho_{b f}\left(\rho_{n f}\right)^{-1} \mathrm{P}_{X}+\mu_{n f}\left(v_{b f} \rho_{n f}\right)^{-1} \operatorname{Pr}\left(U_{X X}+U_{Y Y}\right) \\
& +\sigma_{n f}\left(\sigma_{b f}\right)^{-1} \operatorname{Pr} H a^{2}\left(V \sin (\gamma) \cos (\gamma)-U \sin ^{2}(\gamma)\right)
\end{aligned}
$$

Momentum equation in $Y$ - direction:

$$
\begin{aligned}
& V_{\xi}+U V_{X}+V V_{Y}=-\rho_{b f}\left(\rho_{n f}\right)^{-1} \mathrm{P}_{Y}+\mu_{n f}\left(v_{b f} \rho_{n f}\right)^{-1} \operatorname{Pr}\left(\mathrm{V}_{X X}+\mathrm{V}_{Y Y}\right)+R a_{C} \operatorname{Pr} \Phi \\
& +(\rho \beta)_{n f}\left(\beta_{b f} \rho_{n f}\right)^{-1} R a_{T} \operatorname{Pr} \theta+\sigma_{n f}\left(\sigma_{b f}\right)^{-1} \operatorname{Pr} H a^{2}\left(U \sin (\gamma) \cos (\gamma)-V \cos ^{2}(\gamma)\right)
\end{aligned}
$$

Energy equation:

$$
\theta_{\xi}+U \theta_{X}+V \theta_{Y}=\alpha_{n f}\left(\alpha_{b f}\right)^{-1}\left(\theta_{X X}+\theta_{Y Y}\right)+(L e)^{-1}\left(\Phi_{X} \theta_{X}+\Phi_{Y} \theta_{Y}\right)+\operatorname{Pr} N_{T B T} S c^{-1}\left[\left(\theta_{X}\right)^{2}+\left(\theta_{Y}\right)^{2}\right]
$$


M. J. Uddin et al.

International Journal of Thermofluid Science and Technology (2019), Volume 6, Issue 1, Paper No. 19060101

Concentration equation:

$$
\Phi_{\xi}+U \Phi_{X}+V \Phi_{Y}=\operatorname{Pr} S c^{-1}\left(\Phi_{x X}+\Phi_{Y Y}\right)+S c^{-1} \operatorname{Pr}\left[N_{\text {твтC }}\left(\theta_{X X}+\theta_{Y Y}\right)+N_{\text {твт }}\left(\Phi_{X} \theta_{X}+\Phi_{Y} \theta_{Y}\right)\right]
$$

where we have assumed that $\left(\Delta T / T_{c}\right)<<1$ and $\left(\Delta C / C_{c}\right)<<1$. Also, the dimensionless parameters entered into the above equations (17)-(21) are as follows:

$$
\begin{aligned}
& R a_{T}=L^{3} \beta_{b f} g \Delta T\left(v_{b f} \alpha_{b f}\right)^{-1}, \quad H a=B_{0} L \sqrt{\sigma_{b f}\left(\mu_{b f}\right)^{-1}}, \quad R a_{C}=L^{3} g \Delta C\left(\rho \beta^{*}\right)_{n f}\left(v_{b f} \alpha_{b f} \rho_{b f}\right)^{-1}, \quad \operatorname{Pr}=v_{b f} \alpha_{b f}^{-1}, \\
& N_{T B T C}=D_{T} \Delta T C_{C}\left(D_{B} \Delta C T_{C}\right)^{-1}, S c=\mu_{b f}\left(\rho_{b f} D_{B}\right)^{-1}, \quad L e=\kappa_{b f} C_{C}\left(\left(\rho c_{p}\right)_{b f} D_{B} \Delta C\right)^{-1} \text { and } N_{T B T}=D_{T} \Delta T\left(D_{B} T_{C}\right)^{-1} .
\end{aligned}
$$

\subsubsection{Non-dimensional Boundary Conditions}

The preliminary states and the wall conditions of the enclosure in the dimensionless form are as follows:

For $\xi=0$, the entire domain of the cavities:

$$
\mathrm{P}=0, \theta=0, U=V=0, \Phi=0,
$$

For $\xi>0$,

On all the walls: $U=V=0, \Phi=1$

On the left even and uneven walls: $\theta=1$

On the right even and uneven walls: $\theta=0$

On the horizontal boundaries of the cavities: $\frac{\partial \theta}{\partial n}=0$

\section{Computational Procedures}

Using the boundary conditions (22), the governing equations (17)-(21) of the present problem are solved by the Galerkin weighted residual scheme of finite element method (FEM). The numerical methods used in this problem are very famous and are available in many numerical books such as Zienkiewicz et al. (2005) and Codina (1998). The detailed computational procedures of the numerical method can be found in Uddin et al. (2016, 2017a). In recent times, Uddin and Rahman (2018) have studied the stage by stage of the finite element method using the principal equations of the current problem. In the present problem, the solutions are converged with the following criterion: $\left|\mathbf{G}^{m+1}-\mathbf{G}^{m}\right| \leq 10^{-5}$ where $G$ represents the unknowns of the problem and $m$ is the quantity of repetition. To describe heat transfer distribution, the local Nusselt number $\left(N u_{L}\right)$ is well-defined on the heat source surface as

$$
N u_{L}=-\frac{\kappa_{n f}}{\kappa_{b f}}\left(\frac{\partial \theta}{\partial X}+\frac{\partial \theta}{\partial Y}\right)
$$

Also, integrating the $N u_{L}$, the average Nusselt number is at the heat source is defined as

$$
N u_{a v e}=-\frac{\kappa_{n f}}{\kappa_{b f}} \frac{1}{2} \int_{0}^{2}\left(\frac{\partial \theta}{\partial X}+\frac{\partial \theta}{\partial Y}\right) d Y
$$

\subsection{Grid Sensitivity Test}




\section{J. Uddin et al.}

International Journal of Thermofluid Science and Technology (2019), Volume 6, Issue 1, Paper No. 19060101

The geometry has been sub-divided into finite elements are called grids. To test and assess the grids over the results, we have calculated $N u_{\text {ave }}$ for a different number of grids for a specific condition such as $d_{p}=10 \mathrm{~nm}, R a_{T}=10^{4}, n=3, R a_{C}=10^{3}, \phi=0.05, \Delta C=0.01, C_{C}=1, \Delta T=10 \mathrm{~K}$, $T_{C}=300 \mathrm{~K}$ at $\xi=1$. In this case, the main aim was to find the fixed number of elements within the tube of uneven side walls and plain boundaries where all the results are optimal. A widespread mesh analysis technique is accompanied to assurance the grid-independent solution for the two types of tubes. The grids effects in terms of the $N u_{\text {ave }}$ are demonstrated in Fig. 2. Fig. 2(a) represents the heat transfer rate versus the number of elements of the enclosure of uneven side walls. Fig. 2(b) displays the heat transfer rate versus the fixed number of elements in the enclosure of plain side walls. From the Fig. 2(a), we have seen that the following different number of grids for the enclosure whose left and right boundaries are irregular (not plain) have been inspected: 1340, 2480, 3680, 6256, 16164, 39440, and 68104. We detected that the average Nusselt number rises slowly as the grids of the enclosure increase to a fixed number. The rate of heat transfer is not influenced after a certain number of elements. The value of the average Nusselt number for 39440 grids is equal to that of the consequences for 68104 grids in this case. So, the simulated results of the current problem of an enclosure having uneven walls are taken for 39440 elements which are independent of the grids. Also, we have seen from Fig. 2(b) that the average Nusselt number for 1172, 2362, 3614, 6490, 15564, 38016 and 68300 elements of the enclosure of plain side walls are examined. It is observed that $N u_{\text {ave }}$ is increased progressively when the grids of the tube of plain walls are increased for a specific number of elements. The heat transfer rate is alike afterward. We have seen that the value of the $N u_{\text {ave }}$ for 38016 elements is equal up to three decimal places to that of 68300 elements. Therefore, in this case, the grid size of 38016 for the enclosure of plain side walls is taken to generate the results.

(a)

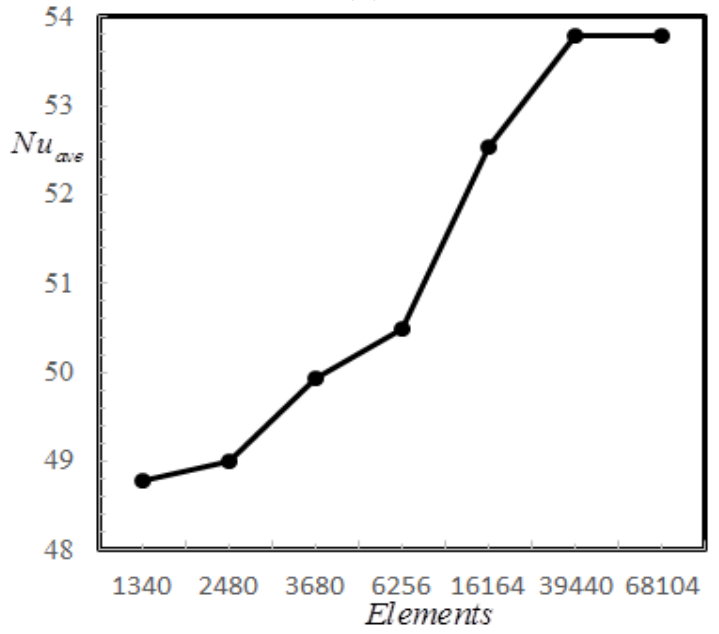

(b)

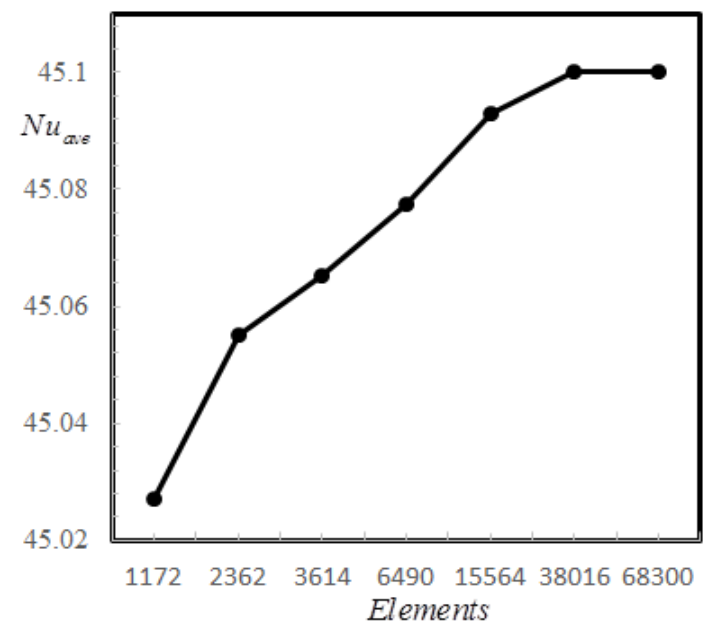

Fig. 2. The grid sensitivity for the (a) tube of uneven left and right walls (b) tube of plain walls for the $\phi=0.05, d_{p}=10 \mathrm{~nm}, R a_{T}=10^{4}, R a_{C}=10^{3}$ at $\xi=1$. 
M. J. Uddin et al.

International Journal of Thermofluid Science and Technology (2019), Volume 6, Issue 1, Paper No. 19060101

\subsection{Code Validation}

Using the present numerical code, the published results of some standard numerical and experimental works are verified. The governing equations and the initial, as well as the boundary conditions, are matched in this case. The numerical investigations of 'Khanafer et al. (2003), Oztop and Abu-Nada (2008), Barakos and Mitsoulis (1994) and Fusegi et al. (1991)' have taken to compare the numerical results for a distinctive situation. In the comparison test, a particular part of the heat equation is considered and the concentration equation is neglected. The similar equations and the nanofluid are taken into consideration. In this case, the $N u_{\text {ave }}$ at the hotter walls is calculated for the different values of the $R a_{T}$ which are shown in Fig. 3(a).

(a)

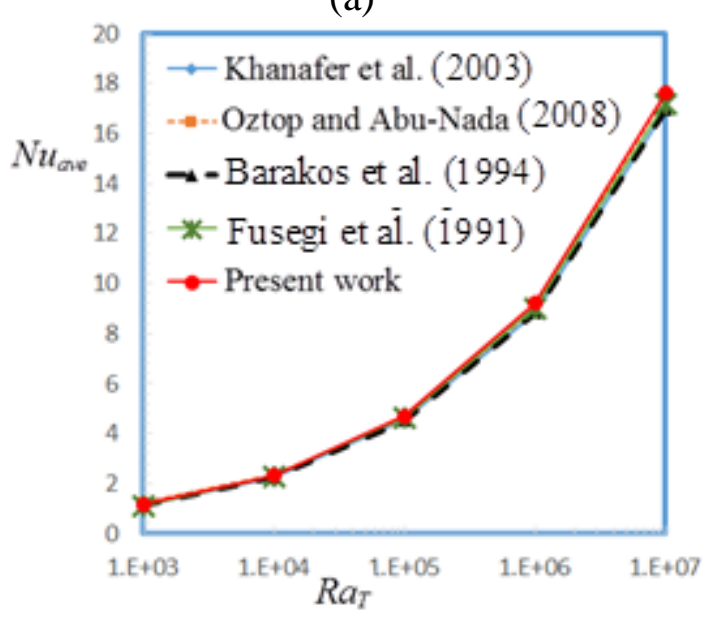

(b)

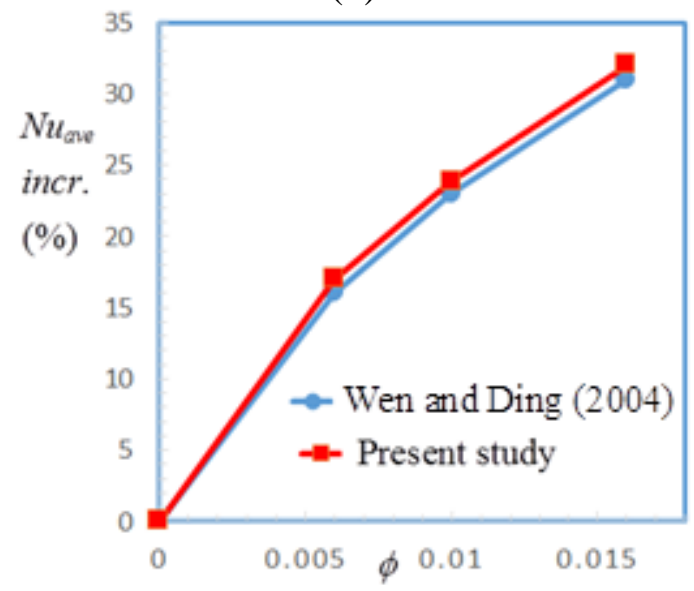

(c)

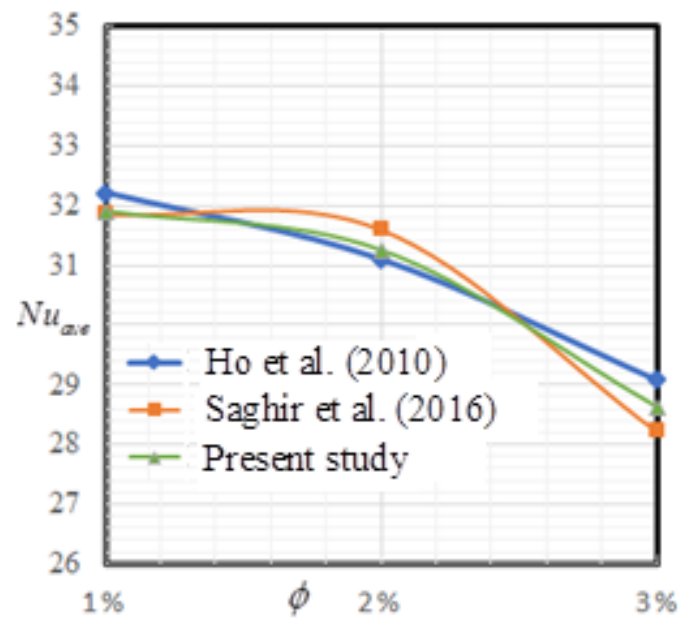

Fig. 3 Comparisons of the present results with the results of (a) Khanafer et al. (2003), Oztop and Abu-Nada (2008), Barakos et al. (1994) and Fusegi et al. (1991) with a fixed condition of $L e^{-1}=0, R a_{C}=0, N_{T B T}=0$ and numerous values of $R a_{T}$ and $\phi$ (b) Wen and Ding (2004) and (c) Saghir et al. (2016) and Ho et al. (2010) for nanoparticle volumefractions. 
M. J. Uddin et al.

International Journal of Thermofluid Science and Technology (2019), Volume 6, Issue 1, Paper No. 19060101

As we have seen that the results using our code is almost similar to that of the benchmark numerical studies. This agreement provides us confidence to take the further outcomes. The results are also matched with the experimental study of Wen and Ding (2004). In this case, the alumina-water nanofluid is considered. The heat transfer augmentation at the entry-length region of the geometry is considered to compare the results. The heat transfer enhancement of the nanomixture compared to the heat transfer of water is calculated. The heat transfer enhancement versus the measure of solid particles using the existing code and the standard study of Wen and Ding (2004) are exhibited in Fig. 3 (b). It can be seen that the outcomes of the Wen and Ding (2004) are similar to the results of the present numerical simulation. This settlement offers a confidence to take further results.

The results of the existing code are also substantiated by the outcomes of a benchmark numerical study of Saghir et al. (2016) and an experimental study of Ho et al. (2010). The comparative results with the experimental $\mathrm{Nu}_{\text {ave }}$ are displayed in Fig. 3(c). In this comparison, the governing equations, the thermophysical properties of alumina-water nanofluid and the differentially heated up square cavity have been selected from the study of Saghir et al. (2016). The present numerical code is used to solve this system. The experimental $N u_{\text {ave }}$ is computed from the study of Ho et al. (2010) by the following expression

$$
N u_{a v e}=0.069\left(\operatorname{Pr}_{n f, h} \operatorname{Pr}_{n f}^{-1}\right)^{0.333}\left(\beta_{n f, h} \beta_{n f}^{-1}\right)^{0.404}
$$

where $\operatorname{Pr}_{n f, h} \operatorname{Pr}_{n f}^{-1}$ is the ratio of the Prandtl number at the high temperature and the Prandtl number at the room temperature for alumina-water nanofluid. In this case, the temperature difference was only 12 degree Celsius. Also, $\beta_{n f, h} \beta_{n f}{ }^{-1}$, is the proportion of the thermal expansion at high temperature and the thermal expansion of the room temperature using alumina-water nanofluid. It is observed from Fig. 3(c) that the existing numerical code has anticipated the point of referenced outcomes. Also, it is reflected in the experimental results. For these reasons, it can be said that the further results of the present study could be contributions in the scientific and engineering arena.

\section{Results and Discussion}

To display and analyze the results, the cobalt-kerosene nanofluid is considered. The properties of solid nanoparticle and the base fluid are used to define the parameters. The thermophysical properties of cobalt nanoparticle at the room temperature are as follows: $\left(c_{p}\right)_{p}=420$ $J_{k g}{ }^{-1} K^{-1}, \rho_{p}=8900 \mathrm{~kg} \mathrm{~m}^{-3}, \kappa_{p}=100 \mathrm{~W} \mathrm{~m}^{-1} \mathrm{~K}^{-1}, \beta_{p}=1.3 \times 10^{-5} \mathrm{~K}^{-1}$. Also, the thermo-physical properties of kerosene at the room temperature are as follows: $\left(c_{p}\right)_{b f}=2090 \mathrm{Jkg}^{-1} \mathrm{~K}^{-1}, \rho_{b f}=780$ $\mathrm{kg} \mathrm{m}^{-3}, \kappa_{b f}=0.149 \mathrm{Wm}^{-1} \mathrm{~K}^{-1}, \beta_{b f}=99 \times 10^{-5} \mathrm{~K}^{-1}$, and $\mu_{b f}=0.00164 \mathrm{~kg} \mathrm{~m}^{-1} \mathrm{~s}^{-1}$. With the properties of the base fluid, the Prandtl number is 23.004 . Now, let us consider the following typical standard values which have been benchmarked in many literatures: $\phi=0.05, \Delta T=10 \mathrm{~K} n=3, T_{C}=301 \mathrm{~K}$, $\Delta C=0.01, d_{p}=10 \mathrm{~nm}, C_{C}=1$. The parameters used in the governing equations (17)-(21) are defined based on the above-stated values as: $D_{T}=4.03 \times 10^{-11}, \quad N_{T B T}=0.06, \quad S c=89239$, 
M. J. Uddin et al.

International Journal of Thermofluid Science and Technology (2019), Volume 6, Issue 1, Paper No. 19060101

$D_{B}=2.36 \times 10^{-11}, \quad N_{\text {TBTC }}=5.71$ and $L e=3.88 \times 10^{5}$. The values of the parameters are not fixed for a particular nanofluid. These parameters values depend on the thermal properties, size, volume fraction and the shapes of the nanoparticle. The solutal Rayleigh number $\left(R a_{c}\right)$ and the thermal Rayleigh number $\left(R a_{T}\right)$ have been altered to find the results.

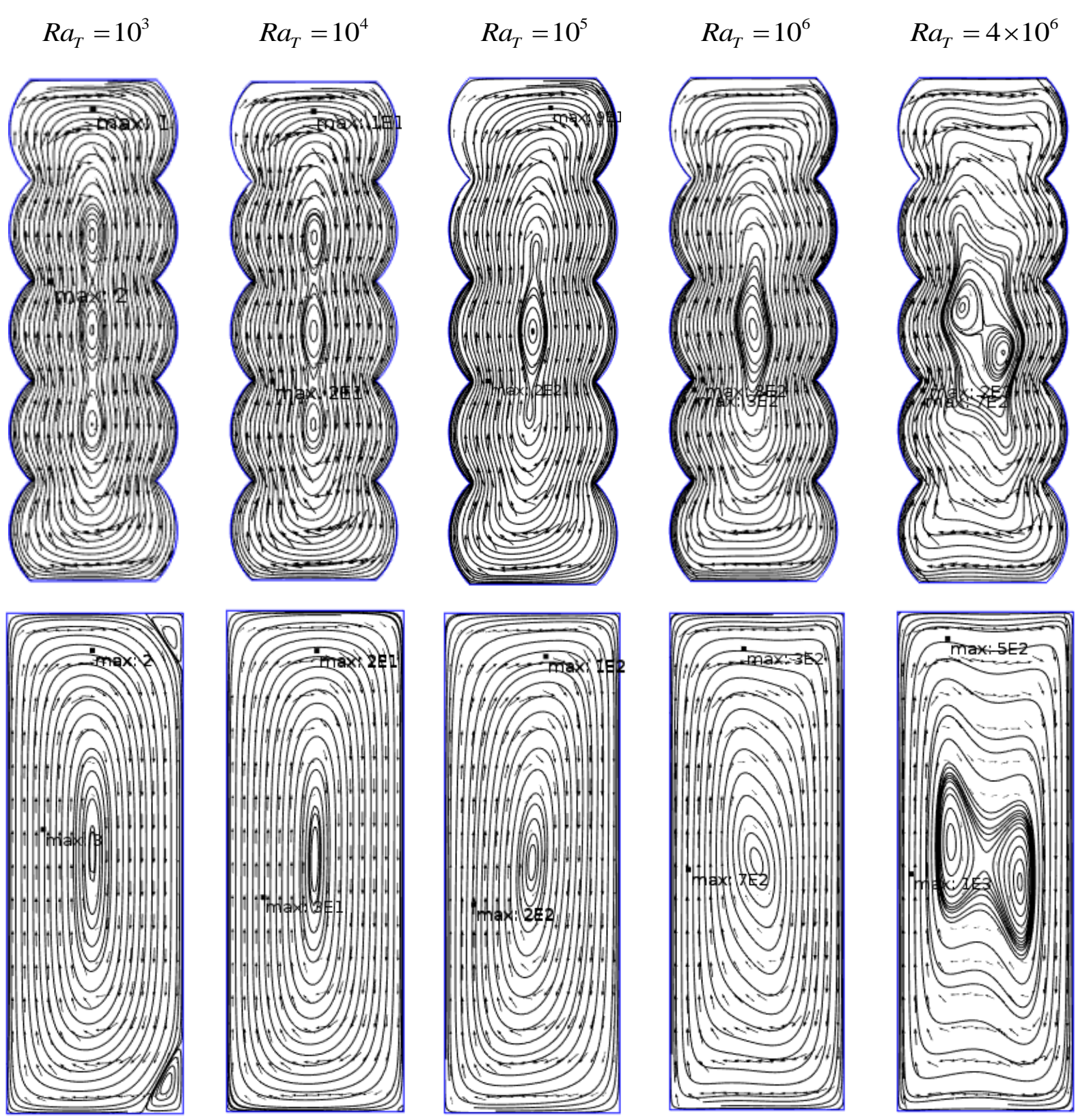

Fig. 4. Streamlines for different values of the thermal Rayleigh number $\left(R a_{T}\right)$ for the selected values of $\phi=0.05, d_{p}=10 \mathrm{~nm}, R a_{C}=10^{3}$ at $\xi=1$. 
M. J. Uddin et al.

International Journal of Thermofluid Science and Technology (2019), Volume 6, Issue 1, Paper No. 19060101

The results of the natural convection heat transfer in cobalt-kerosene nanofluid filled tubeshaped enclosure having a plane and uneven side walls are discussed in this part. The uniform thermal boundary conditions over the even and uneven walls are considered. Using the extensive choice of parameters, the heat transfer mechanism is investigated. In the numerical simulation, the flow and thermal fields and the concentration levels of nanofluid inside the vessel have been analyzed. The heat transfer rate in terms of the local and the average Nusselt numbers have been depicted and analyzed. A comparative study on the effect of the even and uneven walls of the enclosure is also demonstrated. The proportion of the thermal Rayleigh number and the solutal Rayleigh number are determined to be $10^{2}$. The brief nevertheless necessary descriptions of the results have been given.

Figure 4 depicts the comparative distribution of streamlines within the tubes for uneven left and right walls (upper row) and plain side walls (lower row) for different values of the thermal Rayleigh number $\left(R a_{T}\right)$ for the fixed values of $\phi=0.05, d_{p}=10 \mathrm{~nm}, R a_{C}=10^{3}$ at $\xi=1$. We have perceived that the impact of the shape of the boundary walls on the flow field is significantly stricken. The comparative study has been described for two different shapes of the wall conditions. It is observed that the streamlines within the enclosure for uneven left and right walls are significantly congested to each other.

The boundary layers are remarkably visible beside the left and right walls. For the lower values of thermal Rayleigh number, three small clockwise revolving vortices are visible in the middle of the enclosure. As Rayleigh number increases, the three small vortices become one strong vertically elongated vortex and the compactness of the streamlines increases in the middle of the enclosure.

It is important to note that the streamlines are distorted, robust and two connected small vortices are violently oriented anticlockwise for the higher value of the thermal Rayleigh number. On the other hand, for the even boundary walls of the enclosure, it is observed that the distribution of streamlines within the tube is more or less uniform throughout the events. The boundary layers are not significantly visible on the walls. For the lower values of the thermal Rayleigh number, one larger vortex rotates clockwise in the enclosure and two small vortices become visible on the upper and lower right corners of the tube. As Rayleigh number increases, a larger vortex spreads in the entire enclosure, the strength of the streamlines increases and the pattern of the streamlines elongates to the left side. The streamlines become distorted, fortified and robust for the higher values of the thermal Rayleigh number. In this case, two connected strong vortices which are almost horizontally stretched are visible in the middle of the tube. As we have seen that the patterns of the streamlines for even walls are approximately similar to that of the uneven walls for higher Rayleigh number. However, streamlines distributions for uneven walls are seriously different and stronger than that of the even walls for the lower values of the Rayleigh number. The most important disguisable feature is that the streamlines are more visible and vibrant in the tube where two side walls are uneven than that of a tube of plain walls. This is because of the hindrance of the migrations and collisions of solid nanoparticles by the uneven side walls of the enclosure. Also, the flow motion of nanofluid is stricken by the corners of the side walls whereas; the enclosure of the plain walls allows the fluid without any obstacle to flow. 
M. J. Uddin et al.

International Journal of Thermofluid Science and Technology (2019), Volume 6, Issue 1, Paper No. 19060101

Also, because of the same reasons, the maximum values of the surface velocities of fluid flow are higher for even walls of the tube than that of unevenly shaped of right and left walls except for the values of $R a_{T}=10^{5}$, which shows the similar values of the surface velocities. In this case, the critical value has been scrutinized and found $R a_{T}=4 \times 10^{4}$.

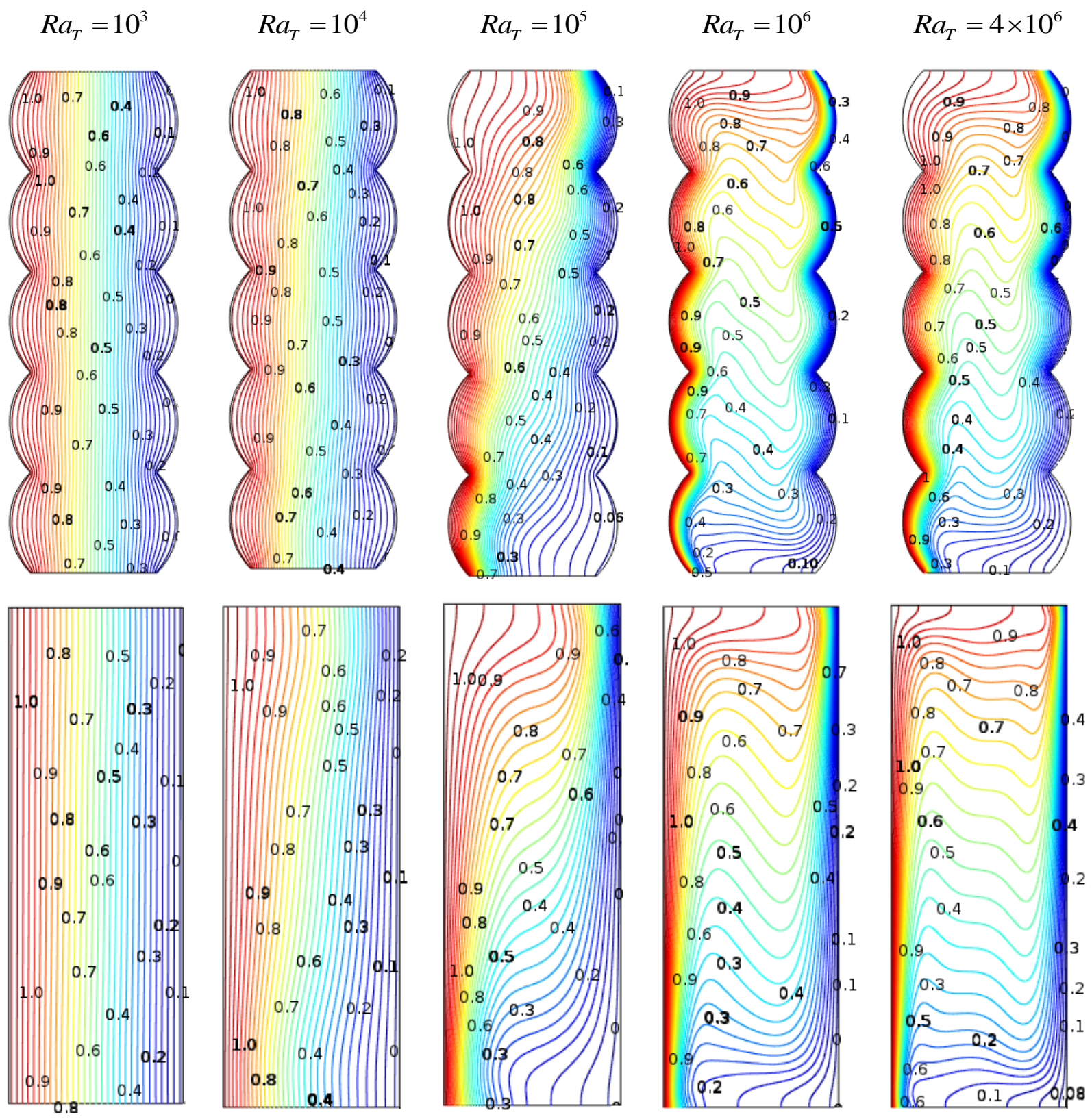

Fig. 5 Isotherms for different values of the thermal Rayleigh number $\left(R a_{T}\right)$ for the selected values of $\phi=0.05, d_{p}=10 \mathrm{~nm}, R a_{C}=10^{3}$ at $\xi=1$.

The distributions of isotherms for uneven left and right walls of the enclosure (top row) 
M. J. Uddin et al.

International Journal of Thermofluid Science and Technology (2019), Volume 6, Issue 1, Paper No. 19060101

and even walls (lower row) have been illustrated in Fig. 5 for different values of the thermal Rayleigh number $\left(R a_{T}\right)$ and for the fixed values of $\phi=0.05, d_{p}=10 \mathrm{~nm}, R a_{C}=10^{3}$ at $\xi=1$. It can be seen that almost similar patterns of the distribution of isotherms have been observed in both types of enclosures. For the tube of even and uneven left and right-side walls, isotherms are slightly engorged from the very beginning for the lower values of the Rayleigh number which means early convection happens in both the tubes but there are some little distinctions can be watched over. Slightly early deformation of isotherms in the middle of the tube of uneven side walls can be observed in this case. This is due to the multiple corners and curved walls of the enclosure where buoyancy force to some extent dominates even with lower temperature differences. However, for the lower values of thermal Rayleigh number, isotherms are parallel to the left and right walls which mean conduction mode of heat transfer dominates in both the tubes. This indicates that the thermal flow of nanofluid is not influenced by the little temperature differences. Also, diffusions and particles random collisions do not happen with the lower value of Rayleigh number. As Rayleigh number increases, for both the cases, the pattern of the isotherm changes; the strength of the isotherms increases and they become distorted and the thermal boundary layer is formed on the hot and cold walls. That means the thermal flow of nanofluid is to a greater extent which indicates the convection mode of heat transfer dominates in the enclosures. Nevertheless, as we compare the changes of isotherms between the tubes of even and uneven side walls, it is observed that the isotherms are more distorted and robust for the plain side walls of the tube than that of uneven side walls. This happened due to the movement of the fluid in the spacious enclosure without any obstacle and the particles can take heat uniformly from the hot wall to the cold wall through the fluid. Hence, the dominating convection mode of heat transfer is slightly higher in the enclosure of plain side walls than that of the tubes of uneven side walls.

Figure 6 displays the isoconcentrations within the tubes of uneven left and right walls (upper row) and even side walls (lower row) for different values of the thermal Rayleigh number $\left(R a_{T}\right)$ for the selected values of $\phi=0.05, d_{p}=10 \mathrm{~nm}, R a_{C}=10^{3}$ at $\xi=1$. It is found that the pattern of the loops of the isoconcentrations within both types of the tubes is similar to that of the respective streamlines for the higher values of the thermal Rayleigh number. In this case, the lines of the isoconcentrations loops spread with the entire tubes. This means that the fluid flow and movement of the species happen due to the higher buoyancy force in the entire space of the enclosure. Nevertheless, in both the cases, the isoconcentrations are congested and clustered to the boundaries of the lower values of the thermal Rayleigh number. This indicates that the motion and collisions of the concentrated nanoparticles along with the molecules within the base fluid is not much influenced by the implied lower temperature differences. There are many disguisable features in the isoconcentrations can be observed between the two types of enclosures. It is important to note that the densities of the isoconcentrations for the uneven side walls of the enclosure are significantly higher than that of the enclosure of even side walls. The level of the isoconcentrations in both the cases is improved as the thermal Rayleigh number is increased and this indicates the uniform distribution of the flow due to the uniformity of the species of the fluid. But the difference is that the levels of the isoconcentrations are increased faster and reaches close to one for the case of uneven than that 
M. J. Uddin et al.

International Journal of Thermofluid Science and Technology (2019), Volume 6, Issue 1, Paper No. 19060101

of even side walls of the enclosure because the corners of the curve walls strike nanoparticles continuously by maintaining the desired temperature differences within the tube. As a result, the species migrations and collisions happen so greatly that the fluid flow captures the entire enclosure.

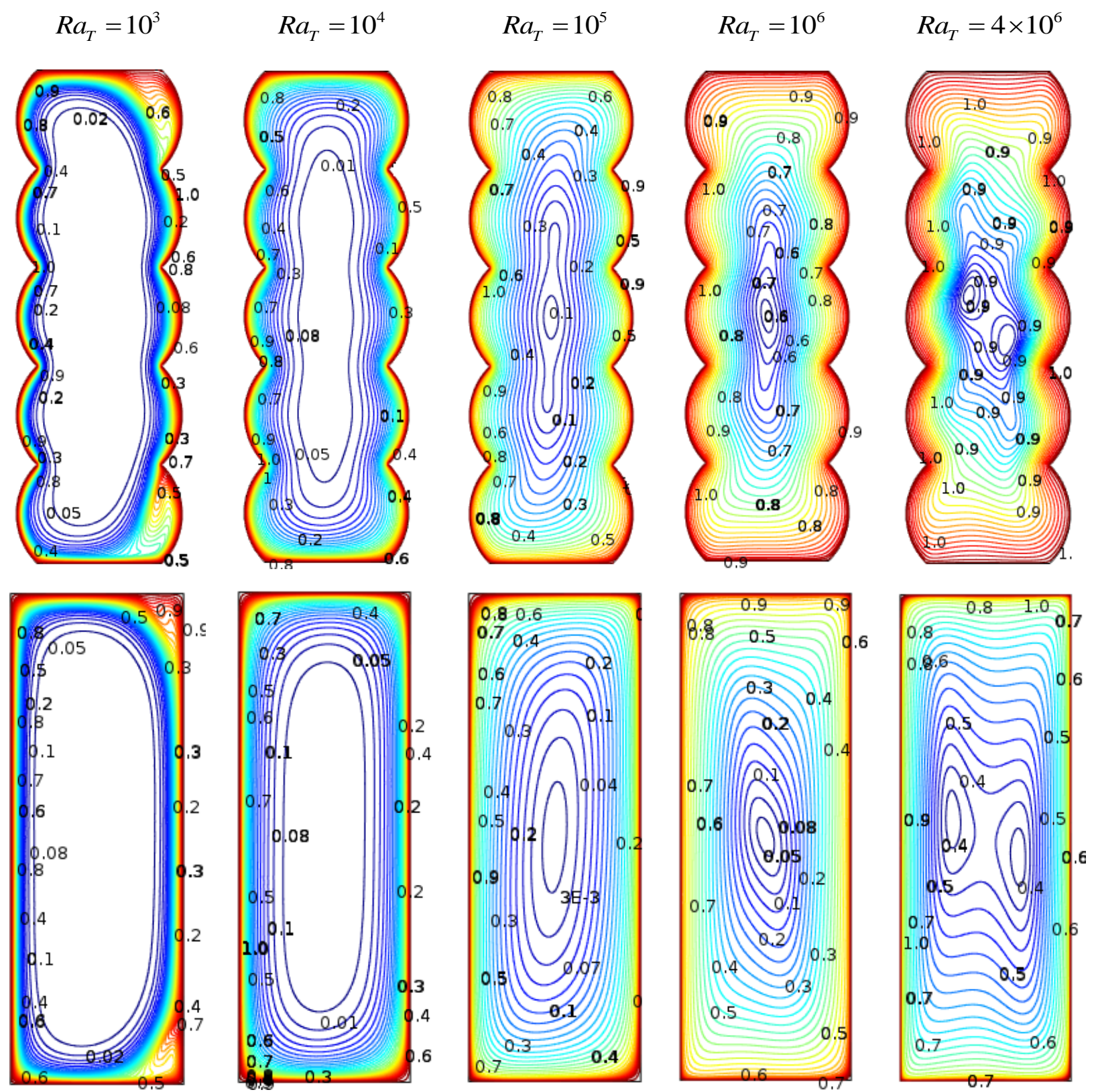

Fig. 6. Isoconcentrations for different values of the thermal Rayleigh number $\left(R a_{T}\right)$ for the selected values of $\phi=0.05, d_{p}=10 \mathrm{~nm}, R a_{C}=10^{3}$ at $\xi=1$. 
M. J. Uddin et al.

International Journal of Thermofluid Science and Technology (2019), Volume 6, Issue 1, Paper No. 19060101

(a1)

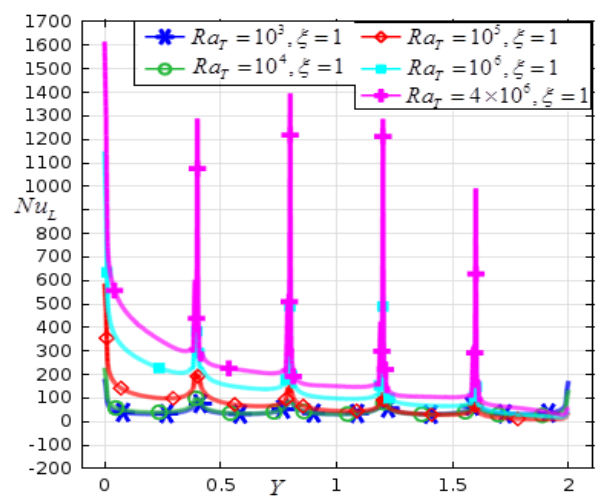

(b1)

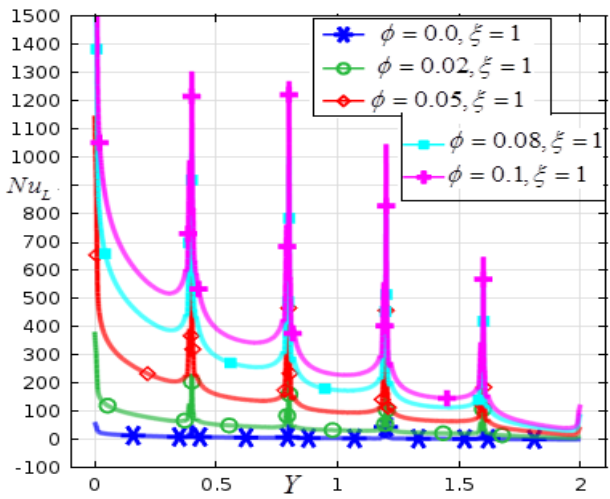

(c1)

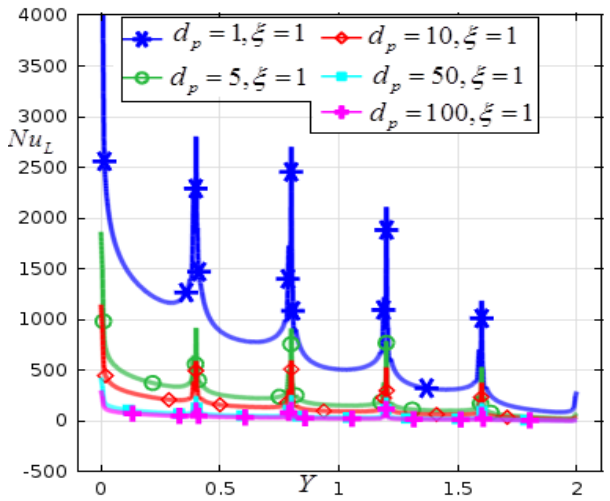

(a2)

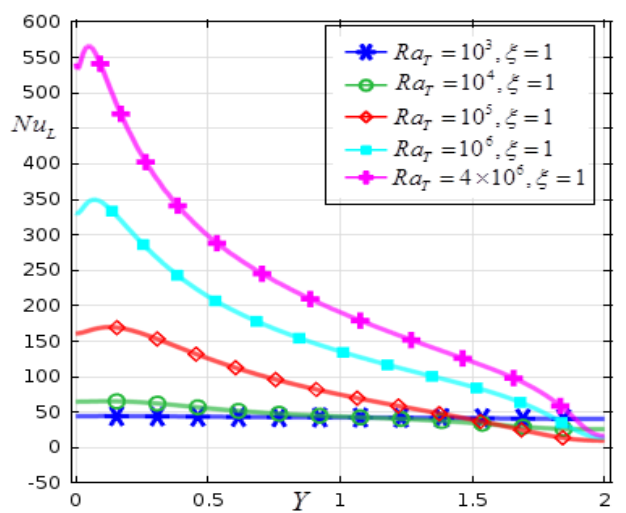

(b2)

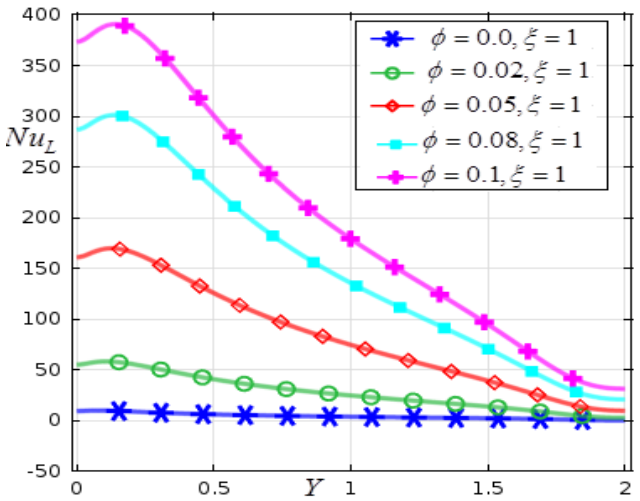

(c2)

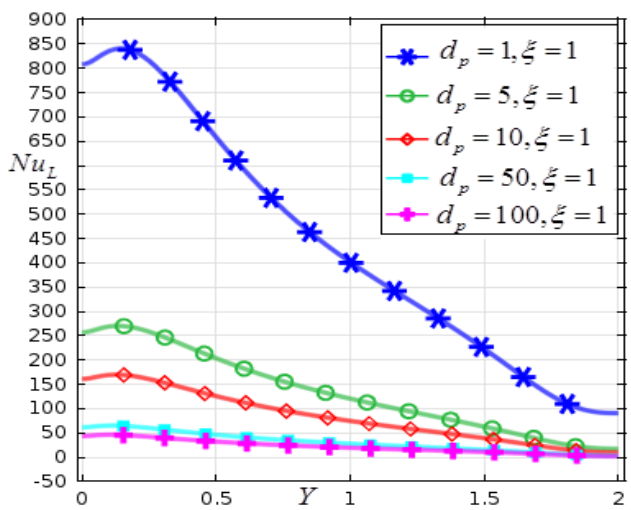

Fig. 7. $N u_{L}$ on the uneven left wall (left column) and even left wall (right column) for different values of the (a) thermal Rayleigh number $\left(R a_{T}\right)$ (b) nanoparticle volume fraction and (c) nanoparticle diameter for $\phi=0.05, d_{p}=10 \mathrm{~nm}, R a_{C}=10^{3}$ at $\xi=1$.

Figure 7 shows the heat transfer distribution in terms of the local Nusselt number on the uneven (left column) and even left hot wall (right column) of the tubes versus $Y$ for different values of the (a) thermal Rayleigh number $\left(R a_{T}\right)$ (b) nanoparticle volume fraction and (c) 


\section{J. Uddin et al.}

International Journal of Thermofluid Science and Technology (2019), Volume 6, Issue 1, Paper No. 19060101

nanoparticle diameter for the selected values of $\phi=0.05, d_{p}=10 \mathrm{~nm}, R a_{c}=10^{3}$ at $\xi=1$. It can be seen from the figure that the boundary shapes of the enclosures greatly impact on the distribution of the $N u_{L}$. The pattern of the distribution of $N u_{L}$ for the tube of uneven side walls is completely distinct from that of the even side walls of the enclosure. The values of $N u_{L}$ are found to be diminished as $Y$ increases. The corners of uneven side walls of the enclosure exhibit remarkably higher $N u_{L}$ whereas at the entry length region of the hot plain wall of the tube shows noteworthy $N u_{L}$. The maximum value of the corresponding $N u_{L}$ for uneven side walls is higher than that of the plain walls of the tube. The $N u_{L}$ versus $Y$ (the hot wall) for different values of the uneven and even side walls are shown respectively in Fig. 7(a1) and 7(a2) and we have seen in general that the $N u_{L}$ is increased if the thermal Rayleigh number is enhanced. The $N u_{L}$ is almost steady for the lower values of the thermal Rayleigh number $\left(R a_{T} \leq 10^{4}\right)$ and the striking change can be observed for $R a_{T}>10^{4}$. Here, $R a_{T}=4 \times 10^{4}$, is the critical value has been found by a series of investigations. Figure 7(b1) and 7(b2) show the $N u_{L}$ versus $Y$ for several values of nanoparticle volume fraction on the uneven and even boundaries respectively. We have seen that for both the cases, the dissemination of $N u_{L}$ upsurges as the nanoparticle volume fraction increases. The value of the $N u_{L}$ is negligible for the base fluid (kerosene) and the distribution is almost a straight line corresponding to the hot wall. This statement is very much true for the tube of the uneven hot wall than that the tube of the even hot wall. Also, the effects of the diameter of nanoparticles in terms of the $N u_{L}$ on the uneven hot wall and even hot wall are portrayed respectively by Fig. 7(c1) and 7(c2). We have noticed that the $N u_{L}$ shrinkages as the diameter of nanoparticle increases. The effect of the diameter of $1 \mathrm{~nm}$ is much significant than that of $5 \mathrm{~nm}$ for both the cases and after $50 \mathrm{~nm}$ the value of the $N u_{L}$ is negligible for the uneven sidewall whereas it is accountable for the even wall of the enclosure although the variation of $N u_{L}$ is almost insignificant.

(a)

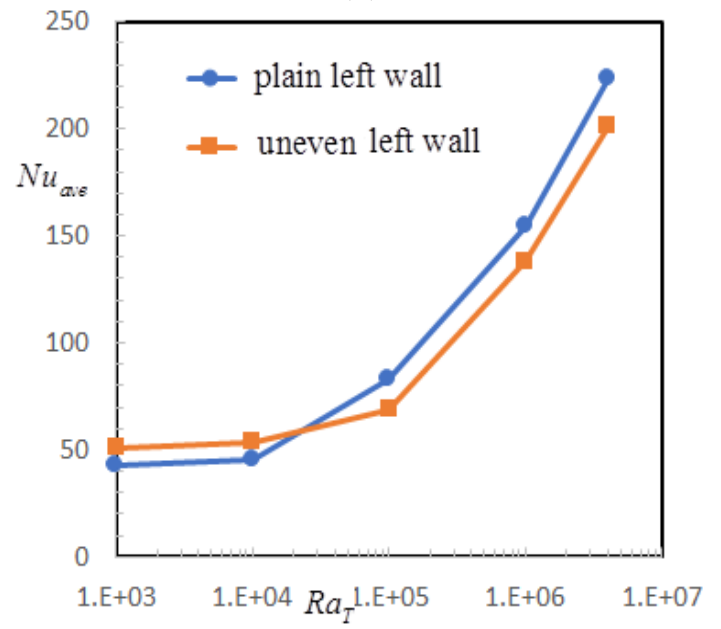

(b) (c)

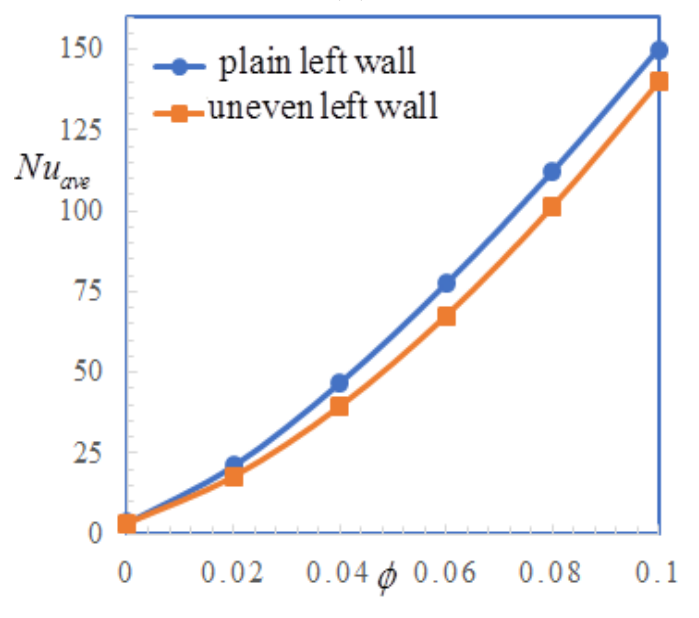

(d) 
M. J. Uddin et al.

International Journal of Thermofluid Science and Technology (2019), Volume 6, Issue 1, Paper No. 19060101
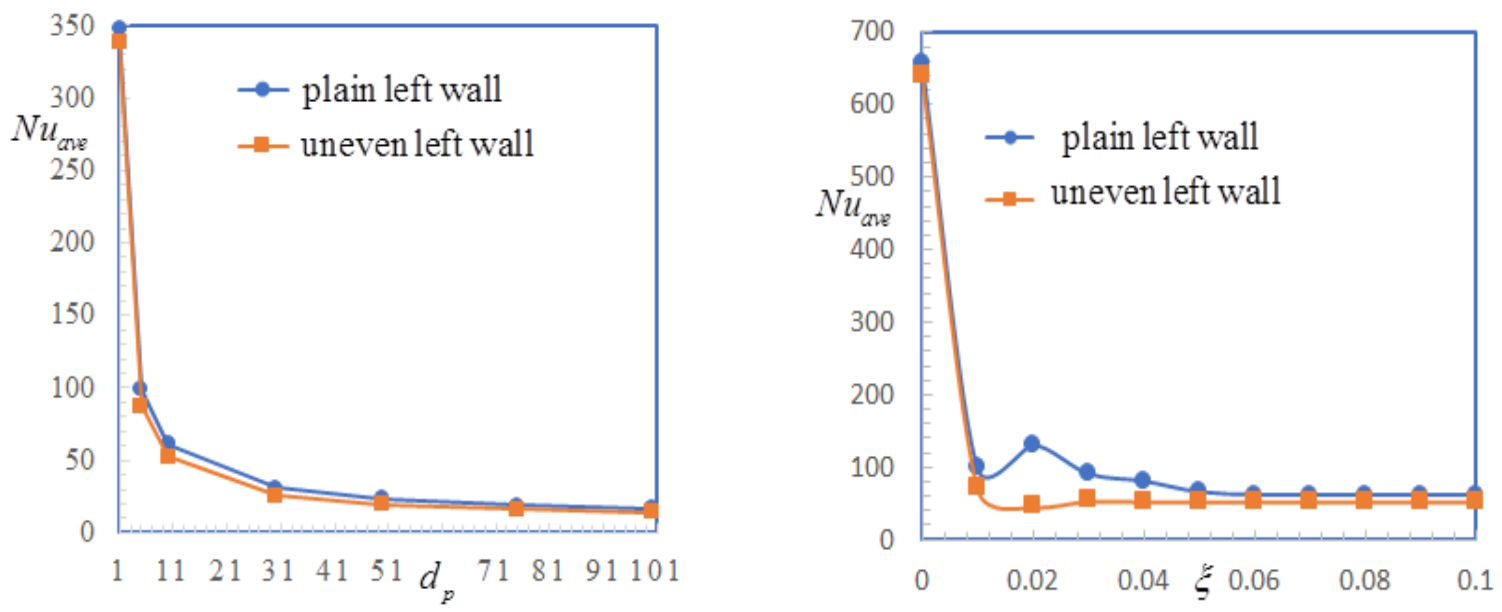

Fig. 8. Average Nusselt number versus the (a) thermal Rayleigh number, (b) nanoparticle diameter (c) nanoparticle volume fraction and (d) time for the uneven and plain left wall for the fixed values of $\phi=0.05, d_{p}=10 \mathrm{~nm}, R a_{T}=4 \times 10^{4}, R a_{C}=10^{3}$ and $\xi=0.2$.

Figure 8 illustrates the average Nusselt number versus the (a) thermal Rayleigh number, (b) diameter of the nanoparticle (c) nanoparticle volume fraction, and (d) time needed the solution to reach in steady state for the uneven and even wall of the enclosure for the fixed values of $\phi=0.05, d_{p}=10 \mathrm{~nm}, R a_{T}=4 \times 10^{4}, R a_{C}=10^{3}$ and $\xi=0.2$. Here, a comparative study of the two types of enclosures for different parameters has been depicted. From Fig. 8(a), an interesting phenomenon is observed. The $N u_{\text {ave }}$ is higher over the uneven left wall of the enclosure for the lower values of the thermal Rayleigh number $\left(R a_{T} \leq 3 \times 10^{4}\right)$ whereas, for the higher values of the thermal Rayleigh number $\left(R a_{T} \geq 3 \times 10^{4}\right)$, plain left wall shows advanced average Nusselt number. In this case, the critical Rayleigh number is $3 \times 10^{4}$. The previous result disclosed that for the lower $R a_{T}$, heat transfer which is conduction mode prevails in the enclosure and convection mode controls for the higher thermal Rayleigh number. Hence, we can conclude that when the conduction mode of heat transfer dominates, the enclosure of uneven boundaries shows better performance whereas when the convection mode of heat transfer governs in the application, the enclosure of plain walls can be appropriate.

The effect of the diameter of nanoparticle in terms of the average Nusselt number on the even and uneven left walls of the tubes are displayed in Fig. 8(b). For both the cases, it shows that as the diameter of nanoparticle increases, the average Nusselt number decreases and the average Nusselt number is approximately steady for $d_{p} \geq 50 \mathrm{~nm}$. This also shows that the average Nusselt number for the different values of nanoparticle diameter is higher for the plain left wall than that of the even left wall of the enclosure. From Fig. 8(c), we have detected that the average Nusselt number is increased when the nanoparticle volume fraction is enhanced in both cases but the increasing trend of the average Nusselt number on the plain left wall is significantly higher than that on the uneven left wall of the enclosure. It is thought-provoking to witness that the value of the average Nusselt number for both cases is practically similar and very lower for the 
M. J. Uddin et al.

International Journal of Thermofluid Science and Technology (2019), Volume 6, Issue 1, Paper No. 19060101

base fluid whereas it is significantly distinguishable between the enclosures and higher for nanofluid. The solution state in terms of the average Nusselt number for a time within nanofluid filled two types of enclosures have been tested in Fig. 8(d). As can be seen that the solutions fluctuate in the initial periods of time and then it becomes steady after a certain time. Initially, the solutions are unstable because the particles of the fluid take time to create equilibrium motion in the mixture and to be settled down with their own path. Particularly, the solution for the enclosure of uneven left and right walls becomes steady earlier than that for the tube of plain walls. This happens due to the corners of the uneven walls which increases the stability of the nanoparticles in the solution.

\section{Conclusions}

The objectives of this work are to investigate convective heat transfer within nanofluid filled two types of enclosures and determine the effects of the shape of the boundaries on the flow and thermal fields. The nonhomogeneous dynamic model of nanofluid is used for the investigation. The governing coupled nonlinear partial differential equations along with the boundary conditions are solved using Galerkin scheme of finite element method. Some of the major findings are as follows:

(i) The dominating convection mode of heat transfer is higher in the enclosure of plain side walls than that of the tube of uneven side walls.

(ii) The levels of the isoconcentrations are optimal for the case of uneven than that of even side walls of the enclosure.

(iii) The maximum value of the local Nusselt number for uneven side walls is higher than that of the plain walls of the tube.

(iv) When the conduction heat transfer controls, the tube of uneven boundaries shows better performance; whereas if the convection mode of heat transfer governs in the application then the tube of plain walls is advantageous.

(v) When the diameter of the nanoparticle is increased, the average Nusselt number is decreased and the average Nusselt number become nearly steady for $d_{p} \geq 50 \mathrm{~nm}$.

(vi)The average Nusselt number for the case of plain as well as uneven walls of the enclosure is practically similar and very low for the base fluid; whereas it is significantly distinguishable between the enclosures and higher for nanofluid.

(vii) The increasing trend of the average Nusselt number with respect to the nanoparticle volume fraction as well as nanoparticle diameter on the plain walls is significantly higher than that on the uneven walls of the enclosure.

(viii) The solution for the enclosure of an uneven left and right walls reaches the steady-state earlier than that of the enclosure with even walls.

\section{Acknowledgment}

M. M. Rahman is grateful to the Sultan Qaboos University for funding under the research grant IG/SCI/DOMS/18/10. 
M. J. Uddin et al.

International Journal of Thermofluid Science and Technology (2019), Volume 6, Issue 1, Paper No. 19060101

\section{Conflict of Interest}

The authors declare that there is no conflict of interest.

\section{References}

Akhavan-Behabadi, M. A., Pakdaman, M. F., \& Ghazvini, M. (2012). Experimental investigation on the convective heat transfer of nanofluid flow inside vertical helically coiled tubes under uniform wall temperature condition. International Communications in Heat and Mass Transfer, 39(4), 556-564.

Alam, M. D., Hossain, S. T., Simanto, M. H. S., Mithu, M. S. U., \& Islam, M. A. (2014). Experimental and Numerical Investigation of an Air to Water Heat Exchanger. In Proc. of the 3rd International Conference on Mechanical, Industrial and Energy Engineering, 26-27.

Barakos, G., Mitsoulis, E., \& Assimacopoulos, D. (1994). Natural convection flow in a square cavity revisited: laminar and turbulent models with wall functions. International Journal for Numerical Methods in Fluids, 18(7), 695-719.

Bianco, V., Nardini, S., \& Manca, O. (2011). Enhancement of heat transfer and entropy generation analysis of nanofluids turbulent convection flow in square section tubes. Nanoscale Research Letters, 6(1), 252.

Choi, S. U. (2008). Nanofluids: A new field of scientific research and innovative applications. Heat Transfer Engineering, 29(5), 429-431.

Choi, S. U. (2009). Nanofluids: from vision to reality through research. Journal of Heat transfer, 131(3), 33106-33115.

Codina, R. (1998). Comparison of some finite element methods for solving the diffusion-convectionreaction equation. Computer Methods in Applied Mechanics and Engineering, 156(1-4), 185-210.

Das, S. K., Choi, S. U., Yu, W., \& Pradeep, T. (2007). Nanofluids: Science and Technology. John Wiley $\&$ Sons.

Fusegi, T., Hyun, J. M., Kuwahara, K., \& Farouk, B. (1991). A numerical study of three-dimensional natural convection in a differentially heated cubical enclosure. International Journal of Heat and Mass Transfer, 34(6), 1543-1557.

Ho, C. J., Liu, W. K., Chang, Y. S., \& Lin, C. C. (2010). Natural convection heat transfer of aluminawater nanofluid in vertical square enclosures: an experimental study. International Journal of Thermal Sciences, 49(8), 1345-1353.

Huminic, G., \& Huminic, A. (2012). Application of nanofluids in heat exchangers: a review. Renewable and Sustainable Energy Reviews, 16(8), 5625-5638.

Khanafer, K., Vafai, K., \& Lightstone, M. (2003). Buoyancy-driven heat transfer enhancement in a twodimensional enclosure utilizing nanofluids. International Journal of Heat and Mass Transfer, 46(19), 3639-3653.

Lotfi, R., Saboohi, Y., \& Rashidi, A. M. (2010). Numerical study of forced convective heat transfer of nanofluids: comparison of different approaches. International Communications in Heat and Mass Transfer, 37(1), 74-78.

Lun-Chun, L., \& Zhen-Hua, L. (2008). Boiling characteristics in small vertical tubes with closed bottom for nanofluids and nanoparticle-suspensions. Heat and Mass Transfer, 45(1), 1-9.

Mahian, O., Kianifar, A., Heris, S. Z., \& Wongwises, S. (2014). First and second laws analysis of a minichannel-based solar collector using boehmite alumina nanofluids: effects of nanoparticle shape and tube materials. International Journal of Heat and Mass Transfer, 78, 1166-1176.

Maxwell, J.C. (1881). A treatise on electricity and magnetism (Vol. 1). Clarendon press. 
M. J. Uddin et al.

International Journal of Thermofluid Science and Technology (2019), Volume 6, Issue 1, Paper No. 19060101

Oztop, H. F., \& Abu-Nada, E. (2008). Numerical study of natural convection in partially heated rectangular enclosures filled with nanofluids. International Journal of Heat and Fluid Flow, 29(5), 1326-1336.

Pakdaman, M. F., Akhavan-Behabadi, M., \& Razi, P. (2012). An experimental investigation on thermophysical properties and overall performance of MWCNT/heat transfer oil nanofluid flow inside vertical helically coiled tubes. Experimental Thermal and Fluid Science, 40, 103-111.

Piletska, E. V., \& Piletsky, S. A. (2010). Size matters: Influence of the size of nanoparticles on their interactions with ligands immobilized on the solid surface. Langmuir, 26(6), 3783-3785.

Rahman, M. M., Rosca, A. V., \& Pop, I. (2015). Boundary layer flow of a nanofluid past a permeable exponentially shrinking surface with convective boundary condition using Buongiorno's model. International Journal of Numerical Methods for Heat \& Fluid Flow, 25(2), 299-319.

Rahman, M. M. (2018). Heat transfer in Fe3O4-H2O nanofluid contained in a triangular cavity under a sloping magnetic field. SQU Journal for Science, 23(1), 56-67.

Rahman, M. M., Pop, I., \& Saghir, M. Z. (2019). Steady free convection flow within a titled nanofluid saturated porous cavity in the presence of a sloping magnetic field energized by an exothermic chemical reaction administered by Arrhenius kinetics. International Journal of Heat and Mass Transfer, 129, 198-211.

Saghir, M. Z., Ahadi, A., Mohamad, A., \& Srinivasan, S. (2016). Water aluminum oxide nanofluid benchmark model. International Journal of Thermal Sciences, 109, 148-158.

Sasmito, A. P., Kurnia, J. C., \& Mujumdar, A. S. (2011). Numerical evaluation of laminar heat transfer enhancement in nanofluid flow in coiled square tubes. Nanoscale Research Letters, 6(1), 376.

Sheikholeslami, M., Gorji-Bandpy, M., Ganji, D. D., \& Soleimani, S. (2013). Effect of a magnetic field on natural convection in an inclined half-annulus enclosure filled with $\mathrm{Cu}$-water nanofluid using CVFEM. Advanced Powder Technology, 24(6), 980-991.

Sun, B., Zhang, Z., \& Yang, D. (2016). Improved heat transfer and flow resistance achieved with drag reducing $\mathrm{Cu}$ nanofluids in the horizontal tube and built-in twisted belt tubes. International Journal of Heat and Mass Transfer, 95, 69-82.

Timofeeva, E. V., Routbort, J. L., \& Singh, D. (2009). Particle shape effects on thermophysical properties of alumina nanofluids. Journal of Applied Physics, 106(1), 014304.

Tiwari, R. K., \& Das, M. K. (2007). Heat transfer augmentation in a two-sided lid-driven differentially heated square cavity utilizing nanofluids. International Journal of Heat and Mass Transfer, 50(9-10), 2002-2018.

Uddin, M. J., \& Rahman, M. M, (2018). Finite element computational procedure for convective flow of nanofluids in an annulus. Thermal Science and Engineering Progress, 6, 251-267.

Uddin, M. J., \& Rahman, M. M. (2017). Numerical computation of natural convective heat transport within nanofluids filled semi-circular shaped enclosure using nonhomogeneous dynamic model. Thermal Science and Engineering Progress, 1, 25-38.

Uddin, M. J., Al Kalbani, K. S., Rahman, M. M., Alam, M. S., Al-Salti, N., \& Eltayeb, I. (2016). Fundamentals of nanofluids: evolution, applications and new theory, International Journal of Biomathematics and Systems Biology. International Journal of Biomathematics and Systems Biology, 2(1), 1-32.

Uddin, M. J., Alam, M. S., \& Rahman, M. M. (2017a). Natural convective heat transfer flow of nanofluids inside a quarter-circular enclosure using nonhomogeneous dynamic model. Arabian Journal for Science and Engineering, 42(5), 1883-1901.

Uddin, M. J., Alam, M. S., Al-Salti, N., \& Rahman, M. M. (2016). Investigations of Natural convection heat transfer in nanofluids filled horizontal semicircular-annulus using nonhomogeneous dynamic model. American Journal of Heat and Mass Transfer, 3(6), 425-452. 
Uddin, M. J., Rahman, M. M., \& Alam, M. S. (2018). Analysis of natural convective heat transport in homocentric annuli containing nanofluids with an oriented magnetic field using nonhomogeneous dynamic model. Neural Computing and Applications, 30(10), 3189-3208.

Uddin, M. J., \& Hoque, A. F. (2018). Convective heat transfer flow of nanofluid in an isosceles triangular shaped enclosure with an uneven bottom wall. Chemical Engineering Transactions, 66, 403-408.

Wen, D., \& Ding, Y. (2004). Experimental investigation into convective heat transfer of nanofluids at the entrance region under laminar flow conditions. International Journal of Heat and Mass Transfer, 47(24), 5181-5188.

Xuan, Y., Li, Q., \& Hu, W. (2003). Aggregation structure and thermal conductivity of nanofluids. AIChE Journal, 49(4), 1038-1043.

Yan, S., Wang, F., Shi, Z., \& Tian, R. (2017). Heat transfer property of SiO2/water nanofluid flow inside solar collector vacuum tubes. Applied Thermal Engineering, 118, 385-391.

Zienkiewicz, O. C., Nithiarasu, P., and Taylor, R. L., (2005). The finite element method for fluid dynamics. Elsevier Butterworth-Heinemann. 